\title{
Notas y comentarios
}

Las ideas y el papel de Raúl Prebisch fueron esenciales en el pensamiento económico y del desarrollo latinoamericano de su época. Sin embargo, las repercusiones de sus contribuciones trascendieron esos ámbitos. Constituyeron un parteaguas, sobre todo si se le valora a partir de un sinnúmero de iniciativas emprendidas desde su gestión en la Comisión Económica para América Latina (CEPAL). Sus aportes tuvieron efectos sumamente positivos en diversos campos del conocimiento, como es el caso del desarrollo regional, el desarrollo urbano y el debate sobre las vinculaciones entre la población y el desarrollo en los países de la región. Por todo ello se consideró que la reseña del profesor Daniel Sotelsek es un trabajo pertinente para revisar y valorar la figura de Raúl Prebisch desde nuestra revista.

La Dirección de la Revista

\section{El pensamiento de Raúl Prebisch: una visión alternativa*}

\author{
Daniel F. Sotelsek Salem**
}

Alguien dijo: Los autores de épocas pasadas se nos aparecen lejanos porque sabemos mucho más que ellos. Ciertamente, pero ellos son lo que nosotros sabemos.

T.S. Elliot

En este documento se revisan la biografía de don Raúl Prebisch y la evolución de su pensamiento. El objetivo central es presentar al lector un enfoque alternativo sobre el modo de evaluar las teorías e ideas de Prebisch aportando los elementos necesarios para juzgar su obra de una manera diferente del enfoque tradicional.

\section{Raúl Prebisch's Thought: An Alternative Vision}

This document reviews Raúl Prebisch's biography and the evolution of his thought. The central aim is to provide the reader with an alternative approach to evaluating Prebisch's

* Este artículo tiene como propósito hacer un repaso de la historia económica del desarrollo postulando una visión sobre la teoría de Raúl Prebisch más cercana a sus fundamentos teóricos que a su divulgación de política económica.

** Universidad de Alcalá. Correo electrónico: daniel.sotelsek@uah.es. 
theories and ideas by contributing the necessary elements to be able to judge his work in a different way from the traditional approach.

\section{Introducción}

En 2006 se cumplieron 20 años de la muerte de Raúl Prebisch, y en 2009, 60 años del manifiesto liminar de la CEPAL, donde se proponía básicamente entender los principales problemas de América Latina. No es seguro que dichos objetivos se hayan cumplido en su totalidad, pero se puede afirmar que la teoría de la CEPAL y de Prebisch sigue constituyendo un elemento de análisis económico al menos complementario de la realidad actual de la región. Todo ello a pesar de que han sido grandes las transformaciones de finales del siglo XX.

La causa por la que se movía Prebisch en esos años no sólo no ha desaparecido, sino que en cierto modo permanece inalterable: la realidad de un mundo subdesarrollado en la mayor parte de nuestro planeta y la tendencia a una mayor desigualdad entre las naciones y sus habitantes.

En este repaso biográfico intentamos mostrar la trascendencia de su obra presentando una interpretación algo modificada sobre la evolución del pensamiento de Prebisch. En primer lugar se hace un repaso de su vida y su pensamiento dentro y fuera del mundo académico. A continuación se describe la evolución de sus ideas en las cinco etapas que suelen aceptarse de manera general. Por último se presenta una forma alternativa de ver la evolución de su pensamiento. Se pretende así reivindicar las ideas de Prebisch en un marco mucho más amplio que el de la Teoría centro-periferia y el proceso de industrialización vía sustitución de importaciones.

\section{Reseña biográfica}

Al hablar de Raúl Prebisch es imposible separar objetivamente sus ideas de su calidad como hombre comprometido con la sociedad en que vivió. Su obra no parece haber sido inútil. De la lectura de los textos de quienes fomentaron sus ideas y los de sus detractores surge como conclusión que su esfuerzo tuvo sentido para Latinoamérica y en general para el Tercer Mundo. Cuando hoy se observan las realidades de China y la India aparecen constantes referencias a cuestiones que están en el núcleo de sus ideas. 
En realidad la biografía de Prebisch es muy extensa: si se agregan a su talento sus largos años de dedicación, la tarea resulta compleja. Sin embargo un somero repaso nos puede centrar en una temática enriquecedora para la economía del desarrollo.

Nació el 17 de abril de 1901 en la ciudad de Tucumán (República Argentina) y murió el 29 de abril de 1986 en Santiago de Chile.

De padre alemán y madre argentina, se graduó en la Facultad de Ciencias Económicas de la Universidad de Buenos Aires y precozmente obtuvo el doctorado en Economía en el año de 1923.

En 1922 trabajó en la Sociedad Rural Argentina (organización marcadamente elitista y con un gran poder político). En esa época las preocupaciones de Prebisch estuvieron orientadas hacia el comercio de la carne y a la ganadería argentina, como lo prueban sus aportaciones a la ley que aprobó el Congreso en 1923. En ella se recogen las propuestas de la Sociedad Rural sobre la creación de un establecimiento que protegiera a los ganaderos de los compradores británicos y estadounidenses, la fijación de un precio mínimo, y la exclusión del mercado interno de los conserveros extranjeros de carnes. ${ }^{1}$

Cabe destacar que junto a tareas de tipo profesional se desempeñó como profesor de economía política en la Universidad de Buenos Aires desde 1925 hasta 1948. Su carrera como funcionario del gobierno argentino comenzó en el año 1925 como subdirector (director adjunto) de la Dirección de Estadísticas, y continuó prácticamente hasta 1943, aunque con intervalos muy marcados de ausencia de responsabilidades políticas. Desde 1927 hasta 1930 encabezó la Unidad de Investigaciones Económicas del Banco de la Nación Argentina. De 1930 a 1932 se desempeñó como subsecretario de Hacienda. En el año de 1931 participó en el grupo que formuló la primera ley del impuesto sobre la renta.

Los primeros pasos de Prebisch como funcionario coinciden con el cambio de gobierno en 1922. Marcelo T. de Alvear, representante de la más rancia aristocracia, reemplazó a Hipólito Yrigoyen en el poder. En 1928 Yrigoyen, el líder indiscutible de la Unión Cívica Radical, retornó a la Presidencia, aunque no por mucho tiempo: su gobierno se vio interrumpido por el golpe militar del 6 de septiembre de 1930 que

${ }^{1}$ Conviene recordar que en 1921 Argentina pasaba por un fuerte periodo de depresión, fruto de la posguerra, que duró hasta 1924. El impacto de la recesión se dejó sentir en el sector ganadero, lo que precipitó un retorno a la agricultura. La propuesta de ley fracasó en la práctica; una explicación más detallada puede verse en Rock, 1989: 217-275. 
fue encabezado por el general J. Uriburu y que dio comienzo a lo que históricamente se conoce como la "Década Infame", en referencia a la corrupción reinante en las elites del poder político.

Desde 1933 hasta 1935 Prebisch fue consejero de los ministros de Agricultura y Hacienda. Se inició allí su preocupación por la banca y las finanzas del país. Cabe destacar que en 1933 participó como representante argentino en la Conferencia Internacional de Economía de la Liga de las Naciones y fue miembro de la delegación argentina que firmó el pacto Roca-Runciman con Gran Bretaña. Este tratado, que fue muy criticado por los nacionalistas argentinos, otorgaba grandes privilegios a los británicos en el comercio bilateral. Por una parte, Gran Bretaña convino en adquirir la misma cantidad de carne argentina que en 1932, y a cambio Argentina consentía -entre otros muchos beneficios- en reducir los aranceles de 350 artículos de importación. ${ }^{2}$

Luego de una breve estancia en el Banco Central de México, fue uno de los responsables de la creación del Banco Central de la República Argentina, y el propio presidente de la nación lo seleccionó entonces para desempeñar el cargo de director general, donde permaneció desde 1935 hasta 1943. Su participación en la creación del Banco Central ha sido motivo de gran controversia; para algunos autores fue él quien con criterio nacionalista, imprimió un tinte original a la propuesta que presentara el entonces gobernador del Banco de Inglaterra, Sir Otto Niemeyer. Sin embargo para los partidarios de Perón fue sólo un instrumento que impulsó ése y otros tantos proyectos de origen e interés británico que no coincidían con los intereses nacionales.

En ese año una nueva revolución de corte nacionalista encabezada por las fuerzas armadas derrocó al gobierno constitucional y preparó el camino al primer gobierno de Juan Domingo Perón.

Con el gobierno peronista en el poder, Prebisch se alejó de la función pública, y desde 1943 hasta 1948 se dedicó exclusivamente a labores de investigación y docencia en la Universidad de Buenos Aires.

En esos años unió a su actividad académica la asesoría a varios gobiernos e instituciones, como el Banco de México (1944) y el Banco Central de Venezuela (1947). Al crearse la CEPAL en 1948 Prebisch comenzó su larga trayectoria fuera de las fronteras; actuó inicialmente

\footnotetext{
${ }^{2}$ Para una crítica al tratado véase: D. Drosdoff, El gobierno de las vacas 1933-1956, citado en Rock, 1989: 287.
} 
como consultor de esa institución y luego fue su secretario ejecutivo desde mediados de 1950 hasta 1963.

En el año de 1955, tras la caída del gobierno peronista con la Revolución Libertadora, regresó como profesor honorario a la cátedra de economía política de la Universidad de Buenos Aires. Más tarde obtuvo los mismos honores en las universidades de Chile, de la Paz (Bolivia) y de San Marcos (Perú).

También fue invitado por el general E. Leonardi, presidente provisional de la República Argentina, a redactar un plan para la recuperación económica de ese país.

En el año de 1962 creó el ILPES (Instituto Latinoamericano de Planificación Económica y Social), en el marco de la CEPAL, y permaneció ligado a él durante mucho tiempo. Conocedor de la problemática inherente a la necesidad de industrializar la región, consideró importante dar un impulso a la planificación.

Desde diciembre de 1964 hasta enero de 1969 cruzó nuevamente las fronteras, en este caso las latinoamericanas, al ser nombrado primer secretario general de la UNCTAD. ${ }^{3}$

A partir de los años setenta se desempeñó como asesor especial de la Secretaría General de la ONU, consejero especial del presidente del BID y del Comité Internacional de la Alianza para el Progreso.

En Latinoamérica muchos afirman que cumplió con un largamente acariciado sueño al dirigir la Revista de la CEPAL desde sus comienzos (1976); difundió en ella por medio de numerosos artículos la recopilación, revisión y replanteamiento de sus tesis originales, donde retomó sus ideas iniciales y, como era su costumbre, unió la teoría con la praxis.

También en estos años (1984) regresó a Argentina como asesor honorario del presidente Alfonsín, especialmente en los temas relacionados con el endeudamiento exterior.

Junto a sus obligaciones habituales siguió dictando numerosos cursos y conferencias hasta que en abril de 1986 lo sorprendió la muerte. Aun así nos legó algunos escritos póstumos como: Crisis del desarrollo argentino: de la frustración al crecimiento vigoroso y "Dependencia, interdependencia y desarrollo". ${ }^{4}$

${ }^{3}$ Órgano no permanente de la Asamblea de las Naciones Unidas creado por la resolución 1995 (XIX) del 30 de diciembre de 1964. Su objetivo fundamental es promover el desarrollo mediante un replanteamiento del comercio internacional.

${ }^{4}$ El primer trabajo fue publicado en Buenos Aires por El Ateneo, en 1986. El segundo apareció en la Revista de la CEPAL, núm. 34, abril de 1988. 
Entre las distinciones que recibió destacan las siguientes: Premio Jawaharlal Nerhu por la Comprensión Internacional (1974); Medalla Honoraria Dag Hammarskold (1977); Premio del Tercer Mundo (1981); Doctor Honoris Causa de las universidades de Columbia (Nueva York), Los Andes (Bogotá), y Punjab (India). ${ }^{5}$ Las limitaciones de espacio nos impiden presentar una relación completa de su extensa bibliografía. ${ }^{6}$

\section{La trayectoria de su pensamiento: una visión ortodoxa ${ }^{7}$}

Se entiende por trayectoria el conjunto de acciones realizadas tanto de tipo profesional, académico, como de investigación; el concepto de evolución está restringido -a mi juicio- al campo de la elaboración teórica. Tal aclaración tiene sentido si se considera que muchos autores, incluido el propio Prebisch, hablan de la evolución de su pensamiento al describir sus etapas, lo que crea confusión a la hora de deslindar la evolución teórica de su experiencia profesional.

Intentaré describir sus etapas en el sentido más tradicional y que coincide con su propia interpretación. Para ello me basaré en la reunión de Pioneros del Desarrollo en el Banco Mundial, donde se ordena su trayectoria en un esquema más o menos cerrado de cinco etapas (Meier y Seers, 1986: 178-206).

Hay consenso en que salió de su país hacia Latinoamérica (cuando ingresó en la CEPAL) y de ahí entró a la realidad del Tercer Mundo en general (la UNCTAD). También existe acuerdo en que sus influencias iniciales provenían de la economía neoclásica, que más tarde adoptó el keynesianismo, y por fin entró al selecto grupo de los Pioneros del Desarrollo.

${ }^{5}$ Cabe mencionar que su regreso a la cátedra y las designaciones que obtuvo en otras universidades sólo implican una carga y un reconocimiento honorífico a los cuales no dedicó más tiempo que sus breves aunque frecuentes viajes a Buenos Aires y a otras ciudades americanas. Sólo dedicó un tiempo considerable, de octubre de 1955 a enero de 1956, al informe que preparó para el presidente de la nación en esas fechas, lo que lo alejó temporalmente de los problemas que se planteaban en el seno de la CEPAL.

${ }^{6}$ Los datos aquí recabados han sido extraídos en su mayoría de: Di Marco (1969), "Homenaje a Raúl Prebisch, 1901-1986" (1986), "Homenaje a Raúl Prebisch" (1987), Alburquerque (1989), Fundación Raúl Prebisch en la República Argentina, y para una revisión sobre la bibliografía de Prebisch véase Sotelsek (1991).

${ }^{7}$ La visión ortodoxa se refiere a que la mayoría de los autores abocados al estudio del subdesarrollo y que conocieron a Prebisch consideran como válidas las etapas del pensamiento que se refieren a continuación. 
Presentaré una división por etapas de acuerdo con el consenso al que hice referencia.

\section{Primera etapa (1920-1943)}

Esta etapa fue la de su primera formación, donde evidentemente recibió una influencia neoclásica.

Sus preocupaciones giraron en torno a la discusión académica de la época; dentro de ella y en coincidencia con sus ocupaciones profesionales, se abocó al análisis de dos campos de la economía que luego serían la base de su análisis keynesiano y de su crítica a la escuela ortodoxa:

a) Los problemas macroeconómicos hacia el interior de la economía argentina.

b) Su análisis de la banca y las finanzas en: "La teoría del interés" (1919); "Ajuste de los salarios al costo de la vida" (1920); "Anotaciones sobre el medio circulante" (1921); "Observaciones sobre los planes monetarios internacionales" (1944); "Moneda y los ciclos económicos en la Argentina" (1944); "El patrón oro y la vulnerabilidad económica de nuestros países" (1944).

En esta etapa acepta la formulación clásica de la teoría del comercio internacional y la teoría estática de las ventajas comparativas de Ricardo. Más aún, a partir de la formulación de Olhin, considera la especialización como la base necesaria para el desarrollo del comercio internacional. Por lo tanto su base teórica es la división internacional del trabajo, y la batalla fundamental que libra es sobre el método.

La crisis del treinta y los graves desequilibrios de la balanza de pagos en Argentina lo llevaron a replantear algunos conceptos y a que poco a poco fuera abandonando la ortodoxia para adoptar un fuerte impulso "industrializador" (Prebisch, 1986b). En sus ideas de esos tiempos iniciales influyó notablemente la depresión mundial. Apremiado por enfrentar las adversas repercusiones de aquel fenómeno, tuvo que ir arrojando por la borda las teorías neoclásicas que lo habían nutrido en su juventud universitaria (Pinto, 1986). 
Segunda etapa (1943-1949)

Estos fueron años de gran reflexión y cuestionamientos, fruto del desengaño político que le produjo la asunción al poder del gobierno peronista.

Su preocupación por las ideas keynesianas fue cada día más fuerte, tanto que en 1947 escribe su Introducción a Keynes como una forma de reconocer su aceptación de esa nueva influencia, especialmente en lo relativo a la recomendación de política económica.

Partió de tres interrogantes:

1) ¿Por qué abandonar las viejas creencias neoclásicas?

2) ¿Por qué es necesario que el Estado sea un agente del desarro110 ?

3) ¿A qué se debe que las políticas formuladas y aplicadas en el centro no obtengan los mismos resultados en la periferia?

Como conclusión de lo anterior se atisba un nuevo patrón de desarrollo hacia adentro, en línea con las ideas que predominaban en la teoría económica del desarrollo de esos años.

Prebisch muestra su preocupación por la teoría económica keynesiana y los problemas de desarrollo en su cátedra de Dinámica Económica, cuyo título implica por sí mismo el comienzo de una nueva forma de considerar la economía en el mundo capitalista.

La cátedra era una creación inédita -inexistente hasta ese momento- en Argentina, que representaba ante todo una nueva perspectiva metodológica para entender la realidad.

El hecho de que se llamara "dinámica" se explica porque la corriente post-keynesiana estaba preocupada por el crecimiento económico. Sin duda alguna los modelos post-keynesianos se dedicaron a estudiar la realidad de una manera mucho más profunda, y por supuesto abarcaron a las instituciones que regían a la sociedad. Era obvio que sus postulados eran más vulnerables que los neoclásicos, que difícilmente descendían a ese nivel. Sin embargo esto les permitió a Prebisch y a otros economistas del desarrollo trascender el análisis keynesiano y aplicar esta metodología al análisis de otros problemas, lo cual los llevó a una concepción estructuralista.

Sus reflexiones teóricas también abarcaron el campo de los elementos históricos estructurales, que establecían esa realidad en América Latina y que tenían su raíz cardinal en lo que llamó: "esquema 
pretérito de división internacional del trabajo implantado por la Pax Británica bajo el palio teórico e ideológico de los economistas clásicos, particularmente Ricardo".

En otro orden de cosas, y desde la economía del desarrollo del largo plazo, Prebisch se adelanta a lo que sería una distinción tradicional entre el desarrollo y el crecimiento: "como economista del desarrollo pensó siempre que la riqueza era un medio y no un fin" (Di Marco, 1969: 516), es decir, que el crecimiento económico era una condición necesaria pero no suficiente para el desarrollo. El aumento de la riqueza, por tanto, debía estar acompañado por una justa distribución; ello era una aproximación al desarrollo económico.

Es útil recordar que en esos años la similitud entre el concepto de crecimiento y el de desarrollo en el marco de la teoría económica era muy grande. Los modelos de crecimiento tipo Harrod-Domar y la elaboración sobre los modelos de acumulación en las economías planificadas habían irrumpido con fuerza en el estudio de la ciencia económica.

También fue notable su interés por la compatibilidad entre la iniciativa privada y la libertad personal. Sobre esta compatibilidad se requiere una breve explicación. Esa asociación de la libertad con la iniciativa privada en la obra de Prebisch la destacan muchos estudiosos, generalmente ligados a una concepción conservadora. Sin embargo creo entender que dicha apreciación se debe relacionar con el hecho de que Prebisch siguió pensando hasta su quinta etapa que el único modo de desarrollo posible es el capitalista. Obviamente en este caso la iniciativa privada y la libertad personal tienen un rol destacado, pero no por ello se puede hablar de un interés característico.

\section{Tercera etapa (1949-1963)}

Al hacerse cargo de la Secretaria Ejecutiva de la CEPAL, junto a un grupo de jóvenes economistas, emprende una cristalización teórica de algunas de las preocupaciones de la etapa anterior.

En realidad es en esta etapa donde Prebisch comienza a figurar como un economista del desarrollo, ya que empieza a preocuparse por entender el problema del subdesarrollo en los países de América Latina y proponer soluciones para superarlo.

Dos libros muestran esta tendencia: Informe sobre la interpretación del proceso de desarrollo económico de América Latina (1949) y El desarrollo económico de América Latina y algunos de sus principales problemas (1949). 
El comienzo de la preocupación aparece en un mundo distinto, transformado por la influencia de: $a$ ) las dos guerras mundiales, $b$ ) la creación de la ONU, c) la implantación del sistema de Bretton Woods, d) la Teoría General de Keynes.

Esto lo llevó a entender las relaciones económicas en el esquema teórico denominado centro-periferia, que tuvo a su vez una vertiente evolutiva: primero, la consideró como una relación cíclica, donde el centro desempeñaba el papel activo y la periferia el pasivo. En segundo lugar aceptó que el esquema centro-periferia era una constelación económica en cuyo centro se encontraban los países industrializados (Prebisch, 1986b).

Surgió entonces una primera tesis que sería el núcleo de su idea central: el deterioro secular de los términos de intercambio, lo que implicó un sesgo inicial para el estudio y análisis de las relaciones comerciales entre los países.

A partir de allí la preocupación inicial se convirtió en una crítica feroz al concepto de desarrollo hacia fuera; consideró que la única solución viable sería una revisión del problema, y para lograr un desarrollo hacia adentro se requería la industrialización.

El tema de la industrialización llevaba a un interrogante: ¿cómo hacerlo? Surgieron así ciertas cuestiones como el esquema de sustitución de importaciones y la intervención estatal por medio de la planificación. Un problema paralelo era determinar la manera en que debía plantearse la relación con los centros, donde se considera: a) la superación del esquema de la división internacional del trabajo, b) la aceptación del proteccionismo como política coyuntural para la periferia hasta resolver las disparidades en la elasticidad de la demanda, c) la solución a la falta de capacidad de ahorro interno.

La industrialización también ayudaba a resolver otro problema latente en muchos países latinoamericanos: la absorción de la mano de obra de baja productividad.

Aunque algunos confundían el concepto de preocupación central con el de idea central, todos estaban de acuerdo en aceptar que su primera preocupación era el progreso técnico, la función que éste cumplía en el desarrollo económico, y su interés particular era la difusión internacional del progreso técnico y quién se apropiaba de sus frutos. Cuando se analiza la teoría económica actual no parece que estas preocupaciones se encuentren en segundo plano; por el contrario es posible que ocupen un lugar importante en las ideas de los economistas. 
En estos años Raúl Prebisch volvió a colaborar con el gobierno argentino (1955). Adoptó una posición ortodoxa, muy alejada de las que día a día sostenía en Santiago.

Un ejemplo de ello se encuentra en Moneda sana o inflación incontenible (1955) y en el Informe preliminar acerca de la situación económica argentina (1955), donde los consejos para Argentina no habían superado su etapa ortodoxa.

En los años finales de esta etapa Prebisch comienza a observar los resultados de sus proposiciones iniciales. En esa época la etapa de sustitución de importaciones para bienes de consumo, denominada la "etapa fácil" encontraba serios inconvenientes, y por lo tanto su propuesta fue pasar a la segunda fase: la sustitución de importaciones de bienes de capital. Nuevamente el problema era: ¿cómo hacerlo? Las propuestas fueron dos: 1) la integración de América Latina para generar un mercado amplio que posibilite una escala adecuada, y 2) incorporar las exportaciones de manufacturas al vínculo comercial.

Cuarta etapa (1964-1969)

Prebisch traspasó las fronteras latinoamericanas y asumió el cargo de secretario general de la UNCTAD. Su objetivo fue la defensa de las relaciones comerciales equilibradas del Tercer Mundo como la única forma viable de lograr el desarrollo de esos países.

En este contexto analizó en forma pormenorizada el verdadero sentido de la ayuda internacional y la cooperación para el desarrollo, abarcando tanto los temas comerciales como los financieros y los tecnológicos (Prebisch, 1986b).

Sus escritos de esta etapa reflejan sus preocupaciones, fruto de los problemas que se plantearon al final de la década de los sesenta en América Latina: Nueva política comercial para el desarrollo (1964), La industrialización y la necesidad de exportar manufacturas (1964), Hacia una dinámica del desarrollo latinoamericano (1964).

Su experiencia en la UNCTAD reforzó su convicción sobre las ventajas de crear un mercado único latinoamericano que favoreciera la consolidación de un mercado interno fuerte e incrementara la posibilidad de obtener una mayor competitividad de cara al exterior. 


\section{Quinta etapa (1969-1986)}

En esta etapa Prebisch abandona las tareas ejecutivas dentro de la CEPAL para ejercer como director del ILPES y posteriormente colaborar en la Revista de la CEPAL. Esto le permitió ocuparse de sus ideas originales y hacer una revisión a fondo, incluyendo temas no tratados en sus primeros escritos; así surgió la preocupación por la distribución de la renta, la inflación como fenómeno social, y la excesiva protección a favor de las clases dominantes.

Conviene considerar que no fue Prebisch el único interesado. La preocupación por estos temas ya se encontraba en el ambiente de la economía del desarrollo en esos años. El binomio crecimiento-redistribución era el principal centro de atención de los economistas que observaban con resignación que el crecimiento de los años sesenta en el Tercer Mundo no desembocaba en una más justa distribución de la renta.

"Aunque el ingreso per cápita promedio del Tercer Mundo ha aumentado en un $50 \%$ con respecto a lo que era en 1960, este aumento se ha distribuido en forma muy desigual entre países, regiones (dentro de un país) y grupos socioeconómicos" (Chenery et al., 1976: 14). ${ }^{8}$

Prebisch y otros autores observaron que en la primera década para el desarrollo hubo crecimiento económico, pero una mala distribución de la renta, lo que implicaba que era inconveniente aceptar como hasta entonces que el análisis del crecimiento debía separarse del análisis de la distribución. Una conclusión más trascendente era que no sólo la distribución internacional (entre países) de la renta era muy desigual, sino que aun cuando las transferencias de rentas operaban en el ámbito internacional, era muy poco probable que en los países subdesarrollados (dada la estructura económica y social) se produjera un crecimiento equitativo.

Esta parecía ser la primera crítica al modo de desarrollo imperante. En tal sentido, Prebisch fue uno de los que se preocuparon por generar una teoría explicativa del funcionamiento del subdesarrollo. ${ }^{9}$

${ }^{8}$ Para una discusión al respecto véase el informe elaborado por los miembros del Institute of Development Studies de la Universidad de Sussex y el Centro de Investigación para el Desarrollo del Banco Mundial (que reúne a un gran número de economistas de los países centrales). Allí se abordan los problemas relacionados con la distribución de la renta, el empleo, el crecimiento y los instrumentos de política económica.

${ }^{9} \mathrm{El}$ interés general era probar que los modelos de desarrollo en boga no incluían ciertos elementos fundamentales, como la definición de los grupos socioeconómicos relevantes, más allá de la división entre los salarios y las utilidades, ni consideraban en el proceso de acumulación los sectores formales e informales de la economía. 
En su revisión se advierte que retorna a sus ideas originales sobre la concepción centro-periferia y percibe que en los centros hay cuestiones aún no resueltas que intenta descubrir.

Observa que en realidad existe un problema originario, advierte que el meollo de la cuestión está en el sistema y su dinámica, por lo que dedica sus diez últimos años de vida a resolver: $a$ ) el planteamiento de la crisis del sistema capitalista periférico, $b$ ) una incipiente propuesta a lo que da en llamar la Teoría de la Transformación.

$\mathrm{Su}$ esquema se transfigura y de la industrialización como idea surge una nueva concepción de la generación y el uso del excedente económico.

En cuanto a lo ideológico, plantea una dura y estructurada crítica a los modelos ortodoxos que han retornado con fuerza a América Latina. También defiende el sistema democrático como un medio viable para que funcione su segunda tesis central: el socialismo liberal, que consiste en producir y consumir libremente de acuerdo con las fuerzas del mercado, mientras el excedente sirve estrictamente a los fines sociales.

Como afirma Fajnzylber (1980), la preocupación de Prebisch sigue siendo la acumulación de capital, tanto del no reproductivo que va a parar al aumento del consumo, como del reproductivo, que aumenta la productividad, el empleo y el excedente. Lo problemático sigue siendo quién se apropia del mismo.

Por último regresa a su país y esto le da la oportunidad de asesorar al presidente Alfonsín en materia de deuda externa y de ajustes económicos internos. Termina sus días con la convicción que las democracias en América Latina no serán viables en la medida en que el sistema no se transforme. "Si hemos de combinar el desarrollo con la igualdad social y el avance político, me parece inevitable la transformación del sistema" (Prebisch, 1986b: 192).

En honor a la verdad, "si no escatimó sobre la sociedad privilegiada de consumo y su impotencia para darle un empleo socialmente benéfico al excedente económico -real o potencial-, tampoco los ahorró para censurar las desviaciones populistas, el engaño y amenaza de la ilusión inflacionista o la hinchazón estéril del aparato del Estado" (Pinto, 1986: 11).

Antes de describir el esquema alternativo, conviene examinar brevemente la posición que al respecto plantea Di Filippo (1988), uno de los discípulos más allegados a Prebisch. Si bien su reflexión sobre las etapas del pensamiento de su maestro se encuentra entre la opinión generalmente aceptada y la hipótesis que se verá en el apartado si- 
guiente, se puede observar un matiz interesante. Él ubica las ideas de Prebisch y su evolución en el marco de influencia de la economía mundial, y de ahí surgen las diferencias respecto a la trayectoria generalmente aceptada. Para ello distingue tres fases principales:

a) Las ideas fundacionales generadas en los años cincuenta, sobre el sistema centro-periferia. Con ello intenta explicar los desequilibrios estructurales de las economías periféricas.

$\mathrm{Al}$ respecto afirma:

a lo largo de este prolongado periodo, las ideas de Prebisch fueron necesariamente evolucionando y transformándose, en términos no sólo de su propia dinámica intelectual, sino de los cambios en la realidad histórica [...] Se trata de su permanente preocupación por los factores que determinan la distribución del progreso técnico y de sus frutos entre Centros y Periferias, así como al interior de cada una de estas sociedades.

b) Esta etapa se refiere a las proposiciones en materia de cooperación internacional que elaboró en la UNCTAD. Allí Prebisch redacta "un verdadero manifiesto de la cooperación Norte-Sur, cuyo contenido sólo puede comprenderse cabalmente si se lo compara con su anterior manifiesto latinoamericano dado a conocer en 1949".

c) En la última fase se dedica al estudio social del excedente; Prebisch presta especial atención al examen de las relaciones de poder que surgen en la estructura social. "Su interés por el uso social del excedente, no es más que una nueva forma de abordar las formas de utilización de los incrementos de la productividad del trabajo".

Sin embargo, la metodología utilizada en el estudio del "capitalismo periférico", ayuda a entender la evolución de algunas economías centrales. Si bien la propia formulación de Di Filippo se acerca más a la consideración teórica, se apoya demasiado en considerar la economía mundial como base del análisis, y cae en la trampa de no incluir su primera formación; asimismo da una importancia teórica a la formulación de la UNCTAD, cuando en realidad es una incursión práctica de Prebisch que en lo esencial no modifica su esquema centro-periferia.

\section{Una visión alternativa}

Hasta aquí la visión tradicional sobre el pensamiento de Prebisch. Intentaremos ahora desarrollar una hipótesis alternativa sobre la forma de considerar la evolución de sus ideas. 
Se debe reconocer que sorprende la poca importancia que se ha concedido a su última etapa, como si todas realmente tuvieran igual jerarquía. ${ }^{10}$ Hablar de Prebisch como un verdadero pionero del desarrollo implica diferenciar entre la trayectoria y la evolución de su pensamiento. Dado que no es recomendable aceptar la objetividad de la economía, parece oportuno indagar sobre sus influencias académica e ideológica.

Si se trata de investigar cuál fue su idea en un momento determinado, y qué razones lo llevaron a pensar en esa forma, la búsqueda debe orientarse fuera del marco intelectual. En cambio, si la pregunta es por qué elaboró las teorías centro-periferia y del capitalismo periférico en momentos donde existían otras interpretaciones teóricas sobre los mismos problemas, conviene estudiar a fondo la lógica de esta teoría. El moverse en ambas direcciones puede resultar confuso y hasta contradictorio, pero parece el método adecuado para conocer el pensamiento del autor.

En función de ello reformularemos las etapas del pensamiento de Prebisch presentando la siguiente alternativa: ${ }^{11}$

\section{La etapa del desconocimiento ${ }^{12}$}

Se puede considerar que Prebisch fue en un primer momento estudiante de una economía compleja, confusa y cambiante como no se había conocido en el siglo Xx. Su aprendizaje de la teoría económica neoclásica y keynesiana hizo a su pensamiento ortodoxo por naturaleza. Aunque su análisis del ciclo económico y de la teoría del comercio internacional no encajaba en la realidad de los problemas latinoamericanos, su idea no se apartó en los aspectos básicos de las predilecciones de la teoría económica tradicional. ${ }^{13}$ Por lo tanto, ello

${ }^{10}$ Las excepciones más claras son los estudios que realizaron Pinto, Di Filippo y Ferrer. Como se verá más adelante, algunos otros autores hicieron comentarios y críticas a su teoría del capitalismo periférico, pero no reconocieron la importancia de la teoría en el pensamiento de Prebisch.

${ }^{11}$ La falta de interés en algún punto en particular implica que estamos considerando esencialmente el aporte de Prebisch a la "economía del desarrollo". Insistir sobre otros aspectos nos puede llevar a disgregar los esfuerzos y dejar de lado el verdadero aporte teórico del autor a la teoría del desarrollo.

${ }^{12}$ Es una clara alusión a la falta de interés por los problemas que empezaban a plantearse en la economía del desarrollo.

${ }^{13} \mathrm{El}$ concepto de predilección está tomado textualmente de Myrdal, quien aunque no define lo que representa, acepta implícitamente que se trata de "aquellas doctrinas 
concuerda con las dos primeras etapas que mencionamos en el punto anterior.

\section{La etapa de la comprensión}

En el segundo momento se presenta el reconocimiento de la forma de funcionar de las economías subdesarrolladas. En todo caso, era necesario matizar el análisis económico tradicional.

Desde que comenzó a trabajar en la CEPAL y quizás unos años antes -que podríamos denominar de transición- hasta los años setenta su pensamiento no evolucionó en un sentido estricto. En realidad había un aporte teórico fundamental.

Si bien la formulación de la teoría centro-periferia constituye un avance teórico en el modo de entender las relaciones de producción e intercambio, en ningún momento describe las relaciones de distribución y apropiación de lo producido. Sin embargo algunos afirman que "a los comienzos aunque no fuera en forma explícita intentó demostrar su ideal redistributivo del ingreso para favorecer a los estratos inferiores" (Di Marco, 1969: 516).

$\mathrm{Al}$ examinar la tesis de Prebisch hay que destacar sus argumentos -harto conocidos- acerca del desequilibrio estructural de la periferia, y adicionar un segundo elemento -base de su concepción dualistarelativo a las formas económicas, sociales y políticas de la apropiación de los incrementos de la productividad que resultan del aumento del progreso técnico, lo que le imprime un carácter original que años después formuló Lewis de manera más consistente.

Las preocupaciones por el empleo y la existencia en los sectores marginales de una fuerza de trabajo destinada a ocupaciones de baja

que generaron antídotos perfectos; elaboradas para hacer inocua la doctrina de la igualdad" (Myrdal, 1959: 150). La influencia de estas predilecciones no sólo fue inmensa en la teoría económica, sino que a su vez era tan difícil aceptarlas como tales, que ni las ideologías en conflicto se percataron de su existencia. En forma sintética podemos decir que las predilecciones eran: a) la armonía de intereses: base ideológica del iusnaturalismo y del utilitarismo que pretendía unir la idea moral con la experiencia del placer y el dolor; $b$ ) el libre comercio, cuyos supuestos son verdaderas abstracciones inexistentes. El ejemplo más claro es el de la "libre competencia", que además de no haber existido nunca, en términos de prestigio cada día cuesta más mantener la utopía; c) el equilibrio estable: este concepto ha servido para justificar el avance histórico de la ciencia sin grandes traumatismos. Muchos economistas de nuestro tiempo no llegan a comprender el significado de una política económica que no tienda al equilibrio. El centro de la predilección encierra un juicio de valor evidente. 
productividad fue la idea implícita en la definición de subdesarrollo de Prebisch.

Su preocupación fue el crecimiento de la economía, y al respecto afirmó: "lo económico no contradice necesariamente a lo social, pero cuando se crece poco se distribuye mal casi siempre" (Prebisch, 1970). Hizo hincapié en la injusticia reinante en el sistema capitalista internacional. Para corregir tal desviación propuso un nuevo esquema teórico, pero al igual que Keynes, quien se inclinó por la intervención estatal para solucionar la crisis del sistema, Prebisch reconoció la injusticia del intercambio internacional, analizó sus causas y planteó soluciones. Ambos eran partidarios del sistema capitalista y del modo de desarrollo imperante, algo esencial para entender su evolución teórica, ya que la tercera etapa marca el fin de su creencia en este modo de desarrollo.

Por ello Prebisch piensa que, corregidas las injusticias, no hay razón para que el patrón de desarrollo hacia el interior de los países sea distinto del que impera en el mundo desarrollado. La evolución de su pensamiento lo lleva a apartarse de la monoeconomía de sus primeras creencias, pero con la idea de que el sistema funcionará bien en el largo plazo si se le aplican medidas correctivas, y así proveerá un máximo bienestar para todos.

\section{La etapa de la proposición}

Un tercer momento, y quizás el más relevante, se produce a partir de la continua revisión del segundo periodo. El hecho de que su tesis centro-periferia siguiera vigente, como en los primeros días en que la planteó, pese al esfuerzo industrializador de algunos países del área deseosos de lograr un elevado crecimiento del PIB en los años sesenta, lo llevó -junto a la revisión de sus recomendaciones iniciales como el esquema sustitutivo en su segunda fase, la promoción de las exportaciones, la generación de un mercado único latinoamericano, etc.- a dar un paso más en su concepción teórica y a observar muchas de las cosas que había desechado, especialmente su creencia en un único modo posible de desarrollo.

El análisis estructural lo llevó a plantear crudamente las relaciones sociales y técnicas de producción, intercambio, distribución y consumo. En la periferia, realizando investigaciones sobre la inflación, el desempleo, la dinámica del excedente, los sistemas de tenencia de la tierra, 
las formas de consumo; y en los centros, examinando la crisis de la capacidad de acumular capital reproductivo.

Como punto de partida retomó el análisis histórico; su preocupación central respecto al progreso técnico evolucionó hacia el estudio del excedente (generación, apropiación, crecimiento y circulación); intentó dar consistencia al esquema centro-periferia al completar su crítica hacia los centros dinámicos. Como conclusión de todo esto planteó la crisis del capitalismo periférico, pero sin duda su creencia en el esquema dinámico del sistema se diluyó y propuso una solución más radical: la transformación del mismo. Sus proposiciones son más profundas, pues de la industrialización pasó al uso social del excedente en el marco de un esquema socialista liberal (Di Filippo, 1987).

Si bien la industrialización -estrategia obvia del modelo centroperiferia- representaba una primera ruptura con la monoeconomía clásica y la posibilidad de plantear una interpretación distinta de la teoría económica, el esquema socialista liberal -también estrategia obvia del modelo capitalista periférico- era la base de una ruptura con el modo de desarrollo capitalista, y en definitiva con el sistema imperante. En ambos casos Prebisch pensaba en una posibilidad real: $e l$ desarrollo del subdesarrollo.

Su evolución consistió en abandonar definitivamente el esquema tradicional de la economía, en criticar el análisis neoclásico y más tímidamente el keynesiano, y en adoptar una postura propia de una teoría global del desarrollo consistente e independiente.

Su tercera intervención en Argentina (1984) tuvo un carácter distinto pues ya había sufrido la decepción de comprobar que un sistema funciona, y por lo tanto declaró que es absurdo creer en una democracia real sin una transformación del sistema.

Como observa Velarde, su etapa "Del Jalón de la Patria" no se aparta de la evolución anterior, pues tanto su primera intervención (1920-1943) como la segunda (1955) se enmarcan en las dos primeras etapas. Si bien en ellas Prebisch intenta describir un proceso de interpretación latinoamericano algo distinto, su análisis conserva rasgos ortodoxos, por lo que sus recetas para su país no son revolucionarias; muy al contrario, descansan en el análisis económico tradicional.

En definitiva, si en su primera etapa no tuvo una concepción teórica del desarrollo, en la segunda ésta es un buen punto de partida, pero tan incompleta que no logra plasmar con fuerza la real preocupación del subdesarrollo, y la tercera es una síntesis acabada, ya que al análisis inicial adiciona ingredientes infaltables en una teoría global 
del desarrollo. En este sentido cabría considerar que su preocupación sólo pasó por tres etapas vitales: del desconocimiento, de la comprensión y del entendimiento y proposición. La propuesta del capitalismo periférico es uno de los temas que hoy intenta desentrañar la teoría económica en el contexto de la globalización económica.

"Para algunos era un revolucionario, para otros un reformista, en realidad era uno de los grandes reformadores en los que el cambio va de la mano con la continuidad". Sería en realidad muy difícil ahora determinar lo que significó Prebisch, pero se puede asegurar que fue un hombre de talento cuya altura intelectual estuvo a la par de la mayor parte de los economistas del desarrollo, que sus estudios han servido para conocer mejor el proceso de subdesarrollo y, como él mismo decía, "me sentiré satisfecho el día que lo que escribí apuradamente en mi vida pero con una gran devoción sirva siquiera para un fundamento crítico de algo nuevo que nosotros no hayamos tenido en cuenta” (apuntes de clase, CEPAL, 1984).

\section{Publicaciones más significativas de Prebisch ${ }^{14}$}

\section{Etapa del desconocimiento}

1922: "Anotaciones sobre la crisis ganadera", Revista de Ciencias Económicas, año 10, serie 2, núm. 17, diciembre, Buenos Aires.

1933: "La Conferencia Económica y la crisis mundial”, Revista Economía, vol. 6, enero, Buenos Aires.

1944: "Antecedentes y proyectos de creación de un Banco Central en Argentina”, en Conversaciones del Dr. Prebisch en el Banco de México D.F., s.l., s.e.

1947: Introducción a Keynes, México, FCE.

1948: "Introducción al curso de dinámica económica", Revista de la Facultad de Ciencias Económicas de la UNBA, vol. 1, núm. 4, julio, Buenos Aires.

1948: "Dictamen del Dr. Prebisch acerca de los anteproyectos sobre Banco Central y bancos", Revista de Hacienda, septiembre, Caracas.

${ }^{14} \mathrm{El}$ presentar este conjunto de publicaciones no implica desechar otros numerosos estudios que realizara Prebisch. Simplemente considero que estos escritos revelan con mayor claridad sus preocupaciones teóricas básicas y también su influencia académica en cada etapa. 
Etapa de la comprensión

1949: El desarrollo económico de América Latina y sus principales problemas, Santiago de Chile, CEPAL (E/CN 12/0089).

1950: "Crecimiento, desequilibrio y disparidades. Interpretación del proceso de desarrollo económico", en N.U. CEPAL, Estudio económico de América Latina, 1949, Nueva York, Naciones Unidas (E/ CN.12/0164).

1951: Problemas teóricos y prácticos del crecimiento económico, México, CEPAL (E/CN 12/0221).

1961: "Falso dilema entre desarrollo económico y estabilidad monetaria”, Boletín Económico de América Latina, vol. 6, núm. 1, marzo.

1963: Hacia una dinámica del desarrollo latinoamericano, México, FCE.

1964: Hacia una política comercial en pro del desarrollo. Informe del secretario general de la UNCTAD, Nueva York, Naciones Unidas.

1968: Hacia una estrategia global del desarrollo: Informe de Prebisch a la II UNCTAD, Nueva York, Naciones Unidas.

1970: Transformación y desarrollo: la gran tarea de América Latina, t. I, México, FCE.

Etapa de la proposición

1976: "Crítica al capitalismo periférico", Revista de la CEPAL, núm. 1. 1978: "Estructura socioeconómica y crisis del sistema", Revista de la CEPAL, núm. 6.

1981: "La periferia latinoamericana en el sistema global del capitalismo", Revista de la CEPAL, núm. 13.

1981: Capitalismo periférico, México, FCE.

1984: "La crisis global del capitalismo y su trasfondo teórico", Revista de la CEPAL, núm. 22.

1988: "Dependencia, interdependencia y desarrollo", Revista de la CEPAL, núm. 34.

\section{Bibliografía}

Adelman, I. (1964), Teorías del desarrollo económico, México, FCE.

Alburquerque Llorens, F. (1989), Raúl Prebisch, Madrid, Ediciones de Cultura Hispánica (ICI). 
Ardnt, H.W. (1981), "Economic Development: A Semantic History", Economic Development and Cultural Change, vol. 29, núm. 2, pp. 457-465.

Beiras, X.M., C. Berzosa, J.L. Sampedro et al. (1987), "Homenaje al profesor Sampedro: ciclo de conferencias", Madrid, Fundación Banco Exterior de España.

Blaug, M. (1968), La teoría económica actual, México, Luis Miralle Hill.

Buzalgo, J. (1987), "Desequilibrio, tiempo y política económica: la escuela de Estocolmo y el estructuralismo latinoamericano”, El Trimestre Económico, vol. 54, núm. 2 (214), pp. 374-383.

Chenery, H. et al. (1976), Redistribución con crecimiento, Madrid, Tecnos.

Chenery, H. y T.N. Srinivasan (1988), Handbook of Development Economics, vol. 1, Amsterdam, Elsevier Science Publishers B.V.

Di Filippo, A. (1988), "Las ideas de Prebisch sobre la economía mundial", Revista de la CEPAL, núm. 34, pp. 165-175.

Di Marco, L. (1969), Economía internacional y desarrollo, Buenos Aires, De Palma.

Fajnzylber, F. (1980), “Comentario sobre el artículo de Raúl Prebisch. Hacia una teoría de la transformación”, Revista de la CEPAL, núm. 11, pp. 170-182.

Furtado, C. (1973), Teoría y política del desarrollo, México, Siglo XXI.

Gurrieri, A. (1982a), La obra de Prebisch en la CEPAL, t. 1, México, FCE.

Gurrieri, A. (1982b), La obra de Prebisch en la CEPAL, t. 2, México, FCE.

"Homenaje a Raúl Prebisch, 1901-1986" (1986), Revista de Comercio Exterior, vol. 36, núm. 5, pp. 379-381.

"Homenaje a Raúl Prebisch" (1987), “Comentarios de las reuniones y conferencias", Madrid, ICI.

Hopenhayn, B. (1988), "Prebisch pensador clásico y heterodoxo", Revista de la CEPAL, núm. 34, pp. 177-188.

Jaramillo, C. (1988), "Prebisch reencontrado y resucitado", Estrategia Económica Financiera, núm. 122, pp. 29-32.

Lewis, A. (1984), "El estado de la teoría del desarrollo", Comercio Exterior, vol. 34, núm. 4, pp. 307-313.

Meier, G.M. y D. Seers (1986), Pioneros del desarrollo, Madrid, Tecnos.

Myrdal, G. (1959), Teoría económica y regiones subdesarrolladas, México, FCE.

Pazos, F. (1988), "Raúl Prebisch, banquero central”, Revista de la CEPAL, núm. 34, pp. 189-204.

Pinto, A. (1986), "Raúl Prebisch 1901-1986", Revista de la CEPAL, núm. 29, pp. $9-16$.

Prebisch, R. (1986), "Cinco etapas sobre mi pensamiento del desarrollo", en G. Meier y D. Seers, Pioneros del desarrollo, Madrid, Tecnos.

Rock, D. (1989), Argentina 1516-1987: desde la colonización española hasta Raúl Alfonsin, Madrid, Alianza Editorial. 
Rodríguez, O. (1986), La teoría del subdesarrollo de la CEPAL, México, Siglo XXI.

Sen, A. (1985), "Cuál es el camino del desarrollo", Comercio Exterior, vol. 35, núm. 10, pp. 939-949.

Sotelsek, D. (1991), Raúl Prebisch y el subdesarrollo: la evolución de sus ideas, tesis de doctorado, Madrid, Universidad de Alcalá de Henares.

Streeten, P. (1983), "Development Dichotomies", World Development, vol. 11, núm. 10, pp. 875-879. 